\title{
The combined use of laser assisted liposuction and endoscopic surgical excision of grade II gynecomastia
}

\author{
Mohammed Mahmoud Abdelaal, MD; Yasser Abdallah Aboelatta, MD; MRCS; \\ Abdelrahman Mohamed Abdelaal, MD; Basim MohammedZaki, \\ MD; Ibrahim Hussien Kamel, MD
}

\author{
Department of Plastic and Reconstructive Surgery, \\ Ain-Shams University, Egypt.
}

\begin{abstract}
Background: Surgical excision of fibroglandular tissue and liposuction of fatty element are the standard now in treatment of grade II gynecomastia. However, the combined use of laser assisted liposuction and endoscopic surgical excision have not been studied before.

Patients and methods: Thirty male patients with grade IIa and IIb were included. 15 patients underwent laser assisted liposuction followed by endoscopic excision of glandular tissues (Group I), and 15 patients underwent conventional (vacuum assisted) liposuction and endoscopic surgical excision (group II).

Results: Patients of group I showed good to excellent outcome with mild edema, indurations, and ecchymosis. Group II patients showed also overall satisfactory results but with moderate to severe edema, ecchymosis, and hematomas.

Conclusion: Endoscopic surgical excision of grade II gynecomastia combined with traditional or laser assisted liposuction can achieve satisfactory results. However, the use of laser assisted liposuction offers additional advantages such as; intraoperative (less bleeding, less operative time) or postoperative either immediately (less pain, indurations, ecchymosis, and edema) or late as improved skin tightness.
\end{abstract}

\section{Introduction:}

The term gynecomastia is derived from Greek words meaning female breast. It is defined as the presence of palpable breast tissue in males and is common in normal individuals, particularly in the newborn period, at puberty, and in the elderly. ${ }^{1}$ It has variable incidence ranging from $30-60 \%$ of men ${ }^{2}$ and it is mostly bilateral, but it may sometimes be unilateral or asymmetric. ${ }^{3}$ Gynecomastia is different from pseudogynecomastia, which is an accumulation of excess fat in a male breast. ${ }^{4}$ It is believed that most cases of gynecomastia are caused by an imbalance of estrogen to androgen ratio. 5

Depending on morphology and volume, gynecomastia is classified, according to Simon, ${ }^{6}$ into: I-Minor breast enlargement without skin redundancy.
IIa-Moderate breast enlargement without skin redundancy.

IIb-Moderate breast enlargement with minor skin redundancy.

III-Gross breast enlargement with skin redundancy that mimics female breast ptosis.

Although the condition may be symptomatic, psychological aspects of surgical treatment is at the same importance to restore normal body image with minimal scar. ${ }^{7}$ Paulus Aegineta (635-690 AD) had been the first to described reduction mammoplasty for gynecomastia using a semi lunar inframammary incision. ${ }^{8}$ The surgical correction of gynecomastia significantly changed in the last decades from open surgery to less invasive procedure including liposuction or combined liposuction and surgery through different incisions. ${ }^{9}$ 
Endoscopic excision of gynecomastia has emerged as a new less invasive approach.

Liposuction represents the other arm of gynecomastia treatment. Traditional liposuction can work well in loose areas; however, in dense areas such as gynecomastia, it is difficult. Refinement in liposuction emerged and involved laser assisted liposuction to overcome this special problem.

Although endoscopic excision and laser assisted liposuction of gynecomastia offer new advantages, combination of both modalities has not been studied before. The aim of this work was to study the benefits and drawbacks of combined both laser assisted liposuction and endoscopic excision of glandular tissues (group I) in comparison to conventional liposuction combined with endoscopic excision of glandular tissues (group II).

\section{Patients and methods:}

This study included thirty male patients complaining of grade II gynecomastia (either IIa or II b). Patients with pseudogynecomastia, unilateral gynecomastia, patients with female like breast (grade III gynecomastia), and patients receiving anticoagulant or antiplatelet drug therapy were excluded.

All patients were referred to endocrinology clinic to exclude secondary causes of gynecomastia. Physical examination included breast size, consistency, skin excess, suspicious masses, and nipple areola position in relation to inframammary fold.

Preoperative ultrasound was done for all patients to confirm the presence of glandular tissue and fatty tissues and to exclude presence of non palpable breast masses.

The idea of this paper was approved by the hospital scientific committee. The benefits and possible drawbacks were discussed with all patients and informed consent was obtained. Patients who accepted the treatment, underwent combined laser assisted liposuction and endoscopic excision of glandular tissues (Group I). Patients who refused this new treatment were treated by conventional (vacuum assisted) liposuction and endoscopic excision of glandular tissues
(Group II).

\section{Surgical technique:}

All surgical procedures were performed under general sedation using IV Profolol or general anesthesia and by the same surgeon (the first author). Patients were marked in the upright position to map the areas of liposuction and surgical excision. Two small incisions $15-20 \mathrm{~mm}$ were made laterally at the anterior axillary line above and below the level of nipple areola complex. Liposuction tumescent was injected through these incisions. About 250-350 cc of tumescent was injected depending on the breast size.

In group I, laser assisted liposuction was done using 1,320nm ND YAG (Cool LipoTM, New Star Lasers, 12 J, 40 Hz). The endpoints of laser procedure were tactile warmth and ease of canula advancement during the procedures, with skin temperature not exceeding $34^{\circ} \mathrm{C}$.

In group II, a liposuction triple-hole canula (usually size 4) connected to a vacuum was used for liposuction of the whole breast fatty tissue. Liposuction was continued until we felt empty breast except for glandular tissue. Liposuction also was done to chest wall beyond markings of the breast and below the inframammary line in order to fade the edges between beast and chest wall.

After liposuction (either traditional or laser assisted), endoscopic excision of glandular tissue was carried on using rigid laparoscope $\varnothing 10 \mathrm{~mm}, 300 \mathrm{~mm}, 0^{\circ}$ (Richard Wolf laparoscopy, Germany). The endoscopic camera was introduced through the upper lateral incision to enable visualization of the remaining tissue and scissor was introduced through the lower incision for dissecting remaining fibroglandular tissue. After complete dissection of glandular tissue, it was removed en bloc or divided into 2 or 3 pieces and extracted through the lower incision. Closure of incision using 5/0 PDS sutures was done and dressing also was applied without drains.

Postoperatively, patients received perioperative antibiotic and analgesic. Preoperative and postoperative digital pictures were taken at least 3 month after 
operation using Nicon-coolpex 995 digital camera (3.3 Mpx, 5X optical zoom).

Results were interpreted by evaluating: the aesthetic outcome of breast shape, the incidence of complications, hospital stay, and time of operative procedure. The degree of aesthetic outcome was evaluated by the treating doctor assessment and the patient satisfaction. The assessment criteria was adopted from the (THE BREAST-Q) scale. ${ }^{10}$ These criteria included overall breast shape, overall shape in relation to chest wall, nipple areola position and shape, breast size, psychosocial relief, and scar quality. Each item was graded as 0 (not accepted), 1(accepted), and 2 (satisfactory). Results were graded as excellent (>75\%), good (51$75 \%)$, fair $(26-50 \%)$, and poor $(<25 \%)$ based on degree of improvement. Complications (hematomas, seromas, nipple areola sensation deficit, nipple areola loss...) were graded into

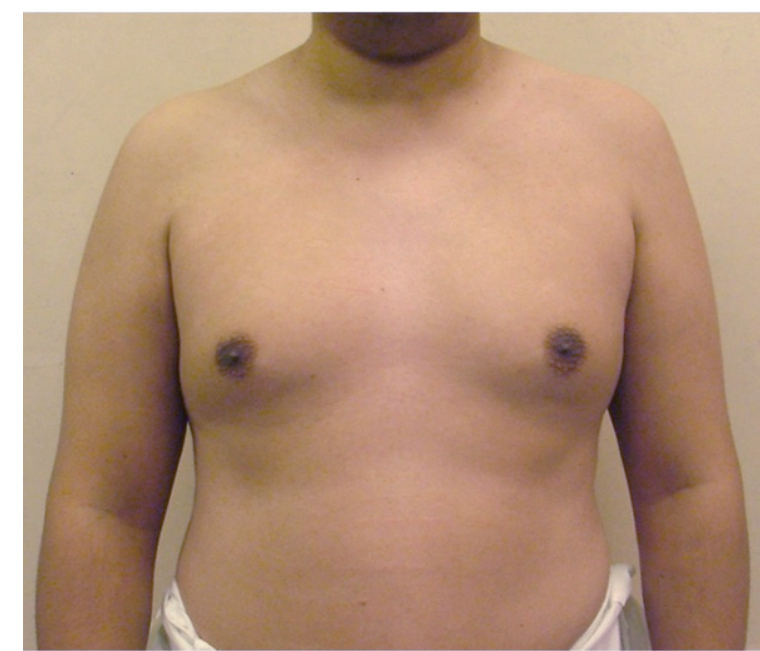

Figure (1): Preoperative and postoperative views of a 23 year's old male patient of group I.
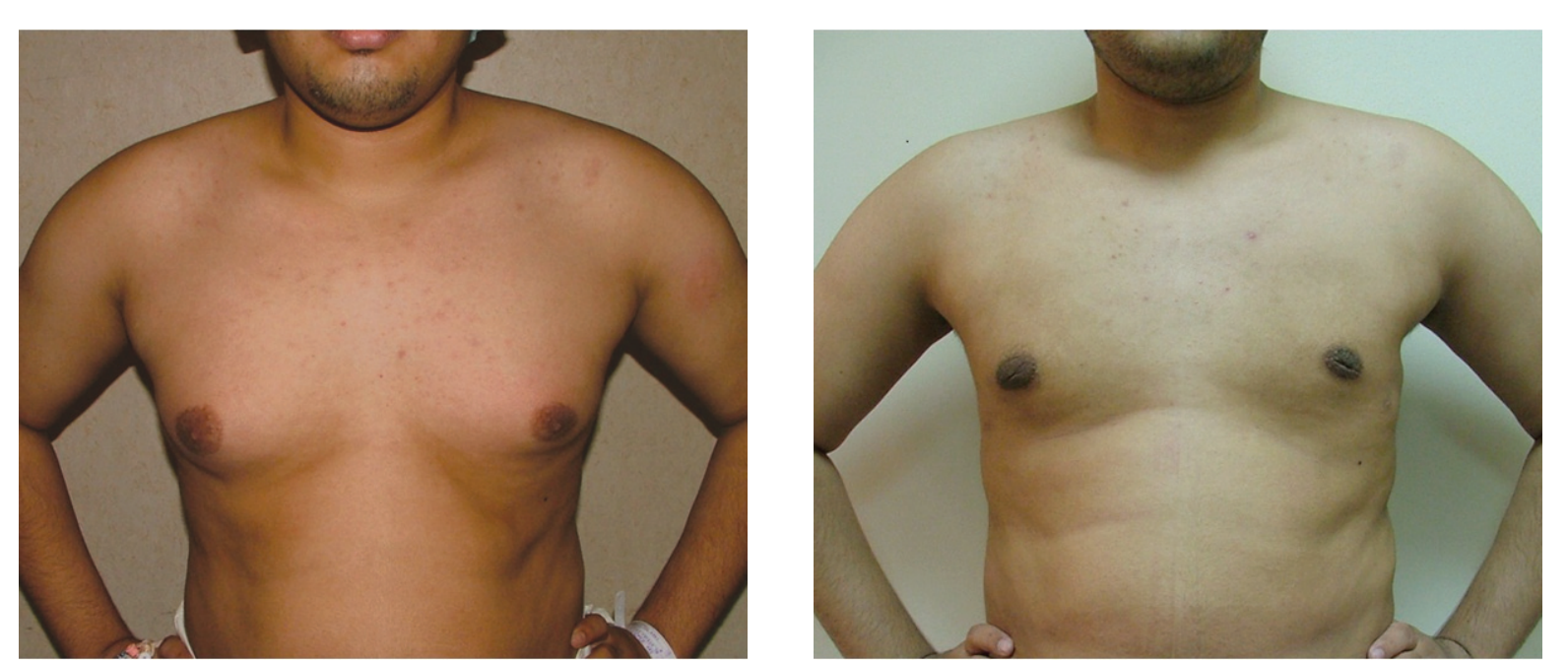

Figure (2): Preoperative and postoperative views of a 21year's old male patient of group II.

either absent (0), mild (1), or moderate to severe (2).

\section{Results:}

This study included thirty male patients complaining of grade II gynecomastia over a period of 2 years. Patients' age ranged from 18-36 years with mean of 23.4 years. The follow up period ranged from 6- 15 months with mean of 8.3 months. Eleven patients (6 patients in group I and 5 patients in group II) were overweight.

In group I, patients' age ranged from 1836 years with mean of 24.6 years. Seven patients had gynecomastia grade IIa and 8 patients had grade IIb. All patients of grade IIa had excellent outcome. Regarding the 8 patients of grade $\mathrm{IIb}$, three patients had excellent outcome and 4 patients had good outcome. All patients showed substantial improved skin tightness with improved skin

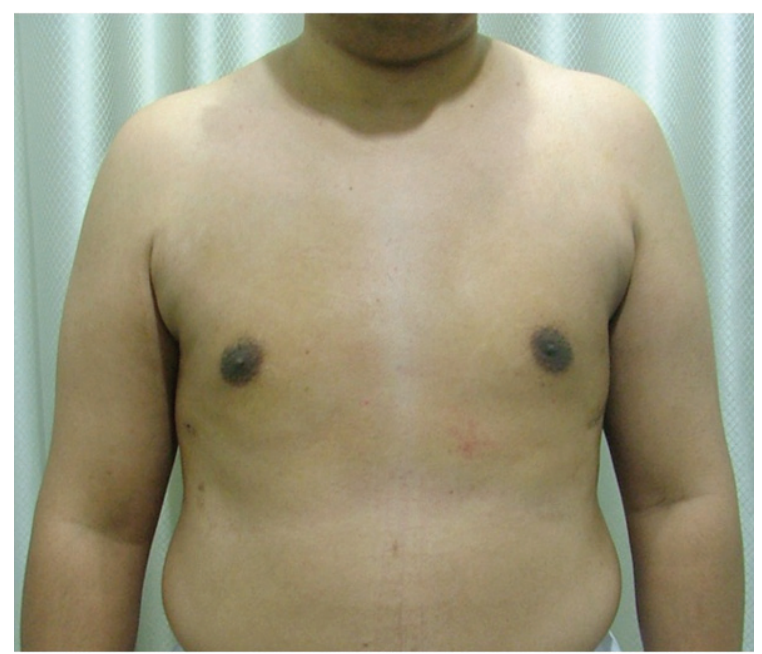


Table (1): Summary of aesthetic improvement in both groups.

\begin{tabular}{|l|c|c|c|c|}
\hline & excellent & good & fair & poor \\
\hline Group I & 11 & 4 & - & - \\
\hline Group II & 9 & 4 & 2 & - \\
\hline
\end{tabular}

redundancy. No visible skin irregularities were recorded except for 2 patients that had minimal irregularities which required no treatment.

In group II, patients' age ranged from 22-36 years with mean of 22.3 years. Nine patients had gynecomastia grade IIa and 6 patients had grade IIb. All patients of grade IIa had excellent outcome. Regarding the 6 patients of grade IIb, four patients had good outcome and 2 patients had fair outcome. All patients showed moderate improvement of both skin tightness and skin redundancy. Visible skin irregularities were recorded in 2 patients. All these results were statically insignificant in relation to group I ( $p>0.05)$.

Regarding complications in group I, no hematoma was recorded and two patients had seromas that were treated by aspiration and compression. One patient had transient tingling sensation in nipple and areola of one breast that resolved after 3 months. Postoperative ecchymosis was mild in all patients and disappeared after 8-12 days. Postoperative edema was mild to moderate and faded within 8-10 weeks.

In group II, 2 patients developed hematoma that required aspiration and compression. In addition, three patients had seromas; 2 out of the 3 patients needed aspiration and compression while the $3^{\text {rd }}$ patient had mild seroma that faded by compression alone. Postoperative ecchymosis was moderate to severe in all patients and disappeared after 15- 20 days. Postoperative edema was mild and faded within 6-8 weeks. No areola dishpot deformity, areola necrosis, infection, or hypertrophic scarring was recorded in both groups. No recurrence or secondary operations were recorded in any patients during study time.

All patients in group I were discharged home at same day of surgery except for 2 patients who stayed an additional day upon their request. In group II, ten patients were discharged home at same day of surgery and five patients spent another day due to marked postoperative pain that required opioid analgesics. Operative procedure time ranged from 85-110 minutes with mean of 98.3 minutes in group I, whereas, in group II, operative procedure ranged from 90- 135 minutes with mean of 108.6 minutes.

\section{Discussion:}

Surgical treatment of gynecomastia aims at adequate treatment of the disease while minimizing apparent scarring. Combined liposuction and excision ensure adequate treatment of the disease. ${ }^{9,11}$

Traditional open resection leaves inframammary or periareolar visible scar that may be more disappointing than the original problem. ${ }^{12}$ The intra-areolar incision or Webster incision also has limited exposure. ${ }^{13}$ In addition, more serious complications can occur such as over-resection leading to breast asymmetry, nipple tethering to pectoral muscles, or unsatisfactory outcome in up to $50 \%$ of cases. ${ }^{14}$

Surgery and liposuction have been combined in different manners. Excision through a single puncture incision of the areola combined with an incision for liposuction at the anterior axillary fold has been described ${ }^{15}$ or through one periareolar stab incision. ${ }^{16}$ Tumescent liposuction was also combined with blind scissors dissection. ${ }^{17}$ Liposuction and vacuum-assisted biopsy device excision of breast tissue was also reported. ${ }^{18}$

The endoscope-assisted subcutaneous mastectomy opened new field in gynecomastia management. ${ }^{19}$ Ohyama et al in $1998^{20}$ described transaxillary endoscopic assisted removal of glandular tissue in gynecomastia through $4 \mathrm{~cm}$ incision. Endoscopic resection of 
gynecomastia was used in different manners; some authors used it only to supervise pull through excision, ${ }^{21}$ others used it to perform direct excision alone, ${ }^{22}$ or in combination with liposuction. ${ }^{23}$

Another method of endoscopic resection in the form of arthroscopic cartilage shaver combined with liposuction was used ${ }^{24}$ that achieved good results. In endoscopic procedure, trans-axillary incisions could be used alone, ${ }^{22}$ or periareollar incisions ${ }^{23}$ or both. ${ }^{24}$

Teimourian and Perlman ${ }^{25}$ in 1983 described liposuction-assisted excision. Fat in gynecomastia consists of firm fibrous connective tissue and compact adipose tissues, which makes conventional liposuction more difficult to perform. If force is exerted repeatedly, it causes great damage to the tissues. For that, interventional ultrasound-assisted liposuction, ${ }^{25}$ external ultrasound-assisted lipoplasty 27 and powerassisted lipoplasty 28 have been developed in the1990s.

Laser assisted liposuction is another step in treatment modalities. Apfelberg ${ }^{29}$ studied laser-assisted liposuction in the early 1990s. Various wavelengths, including 924, 968, $980,1064,1319,1320,1344$, and 1440nm have been used.30

The $1320 \mathrm{~nm}$ wavelength demonstrates greater fat absorption with less tissue penetration and scatter. Therefore, it may be safer for treatment. However, these claims are not well supported and which wavelength is ideal in laser lipolysis is a matter of debate..$^{31}$ Rho et $\mathrm{al}^{32}$ and Trelles et al ${ }^{33}$ were the only who used laser lipoplasty in gynecomastia. They concluded that gynecomastia can be treated effectively and safely with laser lipolysis.

Our technique takes the advantages of both these 2 refinements in the management of gynecomastia. Laser assisted liposuction group achieved overall good to excellent aesthetic outcome with greater patients satisfaction that can be attributed to better skin tightening and fat lipolysis in this dense area. Also laser lipolysis diminished trauma caused by traditional liposuction leading to less postoperative edema, indurations, and postoperative pain. In addition laser liposuction caused coagulation of vessels which resulted in less intraoperative bleeding which made the glandular resection easy and fast. This was manifested by reduced operative time in the laser liposuction group. Furthermore, vessel coagulation caused less postoperative ecchymosis and postoperative hematoma formation.

Endoscopic glandular excision offers resection under vision which minimizes over resection and aesthetic deformity or under resection leading to less satisfactory results and more recurrence. Excision under vision also allows good control of any bleeding even if minor bleeding that minimizes complications and reduces postoperative down time.

Reduced postoperative pain is a sequel of both reduced trauma by laser liposuction and minimal access incisions through endoscopic surgery leading subsequently to shorter hospital stay.

Balch $^{34}$ introduced the trans-axillary approach to minimize scarring. The transaxillary incision leaves hidden scar, but its main disadvantage is the difficulty during glandular resection ${ }^{43}$ and long operative time. ${ }^{35,36}$ These drawbacks could be overcome by the use of endoscopy that allows under vision resection and shortening of the operative procedure time that is helped by the reduced bleeding secondary to the effect of laser lipolysis.

The main disadvantage of our technique is the cost of equipments which are not available in every institution. In addition, the technique needs to some extent slightly slow learning curve.

The combined use of laser assisted liposuction and endoscopic surgical excision of gynecomastia represents a forward step in the road of management. Further randomized blindly controlled studies on larger patient population are warranted in further researches.

\section{Conclusion:}

Endoscopic surgical excision of grade II gynecomastia combined with traditional 
or laser assisted liposuction can achieve satisfactory results. However, the use of laser assisted liposuction offers additional advantages such as; intraoperative (less bleeding, less operative time) or postoperative either immediately (less pain, indurations, ecchymosis, and edema) or late as improved skin tightness.

\section{References:}

1- Nydick M, Bustos J, Dale Jr JH, Rawson RW: Gynecomastia in adolescent boys. JAMA 1961; 178: 449-454.

2- Nuttall FQ: Gynecomastia as a physical finding in normal men. $J$ Clin Endocrinol Metab 1979; 48: 338-340.

3- Nicolis GL, Modlinger RS, Gabrilove JL: A study of the histopathology of human gynecomastia. $J$ Clin Endocrinol Metab 1971; 32: 173-178.

4- Wilson JD, Foster DW, Kronenberg HN and Larsen PR: Disorders of breasts in men. In: Williams textbook of endocrinology. Wilson JD, Foster DW (Editors); Philadelphia, Pa: WB Saunders (Publisher); 9th edn.; 1998; p.885-893.

5- Mathur R, Braunstein GD: Gynecomastia: Pathomechanisms and treatment strategies. Horm Res 1997; 48: 95-102.

6-Simon B, Hoffman S, Kahn S: Classification and surgical correction of gynecomastia. Plast Reconstr Surg 1973; 51 (1):48-52.

7- Hammond D: Surgical correction of gynecomastia. Plast Reconstr Surg 2009; 124 (Suppl.): 61e.

8- Aegineta P: The Seven books of Paulus Aegineta (translated) London: Sydenham Society (Publisher); Book 4 vol 2; 1847; p. 334-335.

9- Rohrich RJ, Ha RY, Kenkel JM, Adams WP Jr: Classification and management of gynecomastia: Defining the role of ultrasound assisted liposuction. Plast Reconstr Surg 2003; 111: 909-923; discussion 924-925.

10-Pusic AL, Klassen AF, Scott AM, Klok JA, Cordeiro PG, Cano SJ: Development of a new patient-reported outcome measure for breast surgery: The BREAST-Q. Plastic \& Reconst Surgery 2009; 124(2):
345-353.

11-Hammond DC, Arnold JF, Simon AM, Caparo PA: Combined use of ultrasonic liposuction with the pull through technique for the treatment of gynecomastia. Plast Reconstr Surg 2003; 112: 896-897. Discussion.

12-Morselli PG. "Pull through": A new technique for breast reduction in gynecomastia. Plast Reconstr Surg 1996; 97: 450-454.

13-Barsky AJ, Kahn S, Simon BE: Principles and practice of plastic surgery. New York: McGraw-Hill (Publisher); 2 ${ }^{\text {nd }}$ edn.; 1964.

14-Bracaglia R, Fortunato R, Gentileschi $\mathrm{S}$, Seccia A, Farallo E: Our experience with the so-called pull-through technique combined with liposuction for management of gynecomastia. Ann Plast Surg 2004; 53: 22.

15-Mentz HA, Ruiz-Razura A, Newall G, Patronella CK, Miniel LA: Correction of gynecomastia through a single puncture incision. Aesthet Plast Surg 2007; 31: 244-249.

16-El-Shafey E: Combined use of liposculpture with the periareolar pullthrough technique for the treatment of gynecomastia, Egypt. J Plast Reconstr Surg 2007; 31(1): 31-36.

17-Yoho R: Description of gynecomastia excision surgery using tumescent liposuction and scissors dissection technique. American Journal of Cosmetic Surgery 2002; 19(3).

18-Ryu JW: Treating gynecomastia with ultrasound - guided vacuum - assisted biopsy device as a cosmetic method. $J$ breast cancer 2010; 13 (1): 27-30.

19-Eaves FF, Bostwick J, Nahai F, Murray DR, Styblo TM, Carlson GW: Endoscopic techniques in aesthetic breast surgery. Augmentation, mastectomy, biopsy, capsulotomy, capsulorrhaphy, reduction, mastopexy, and reconstructive techniques. Clin Plast Surg 1995; 22: 683-695.

20-Ohyama T, Takada A, Fujikawa M, Hosokawa K: Endoscope-assisted transaxillary removal of glandular tissue in gynecomastia. Ann Plast Surg 1998; 
40(1): 62-64.

21-Ramon Y, Fodor L, Peled IJ, Eldor L, Egozi D, Ullmann Y: Multimodality gynecomastia repair by cross-chest power-assisted superficial liposuction combined with endoscopic-assisted pullthrough excision. Ann Plast Surg 2005; 55(6): 591-594.

22-Fan L, Yang $\mathrm{X}$, Zhang $\mathrm{Y}$, Jiang J: Endoscopic subcutaneous mastectomy for the treatment of gynecomastia: A report of 65 cases. Surg Laparosc Endosc Percutan Tech 2009; 19(3): 85-90.

23-Sim HB, Hong YG: Endoscope-Assisted Transaxillary Approach in Gynecomastia Correction. J Korean Soc Aesthetic Plast Surg 2008; 14(2): 113-119.

24-Petty PM, Solomon M, Buchel EW, Tran NV: Gynecomastia: Evolving paradigm of management and comparison of techniques. Plast Reconstr Surg 2010; 125(5): 1301-1308.

25-Teimourian B, Pearlman R: Surgery for gynecomastia. Aesthetic Plast Surg 1983; 7: $155-157$.

26-Zocchi ML: Ultrasonic-assisted lipectomy. Adv Plast Reconstr Surg 1995; 11: 197.

27-Silberg BN: The technique of external ultrasound-assisted lipoplasty. Plast Reconstr Surg 1998; 101(2): 552.

28-Fodor PB, Vogt PA: Power-assisted lipoplasty (PAL): A clinical pilot study comparing PAL to traditional lipoplasty (TL). Aesthetic Plast Surg 1999; 23(6):
379- 385 .

29-Apfelberg D: Laser-assisted liposuction may benefit surgeons and subjects. Clin Laser Mon 1992; 10: 259.

30-Mc Bean J, Katz B: Laser lipolysis: An update. J Clinical Aesth Dermato 2011; 4 (7): 25-34.

31-Parlette EC, Kaminer ME: Laser assisted liposuction: Here's the skinny. Semin Cutan Med Surg 2008; 27: 259-263.

32-Rho YK, Kim BJ, Kim MN, Kang KS, Han HJ: Laser lipolysis with pulsed 1064 $\mathrm{nm} \mathrm{Nd}$ : YAG laser for the treatment of gynecomastia. Int $J$ Dermatol 2009; 48(12): 1353-1359.

33-Trelles MA, Mordon SR, Bonanad E, Moreno Moraga J, Heckmann A, Unglaub F, Betrouni $\mathrm{N}$, Leclère FM: Laser-assisted lipolysis in the treatment of gynecomastia: A prospective study in 28 patients. Lasers Medical Science. DOI: 10.1007/s10103-011-1043-6.

34-Balch CR: A transaxillary incision for gynecomastia. Plas Reconstr Surg 1978; 61: 13-16.

35-Boni R: Tumescent power liposuction in the treatment of the enlarged male breast. Dermatology 2006; 213: 140.

36-Yavuz M, Kesiktas E, Kesiktas N, Acarturk $\mathrm{S}$ : Lighted retractor-assisted transaxillary approach in gynecomastia correction. Ann Plast Surg 2004; 53: 22. 